\title{
REPORT OF THE EXAMINATION OF THE — REGI- MENT, U. S. ARMY, FOR NERVOUS AND MENTAL DISEASES.
}

By K. M. BOWMan, A. B., M. D., Captain M. R. C., U. S. Army, General Hospital No. 6, Fort McPherson, Ga.,

Assistant Physician, Bloomingdale Hospital.

Subjoined are the method of examination and the results obtained in the examination of a newly formed regiment in our army for the presence of nervous and mental diseases. The method of examination was worked out by the writer. It is not claimed that there is anything new in the scheme, but it is felt that the careful detailing of a method of examination, together with the results obtained by the use of the method in examining 1189 men, may be of some value.

The examination was composed of two parts: first, a rapid routine examination and second, a careful examination of all suspects obtained from the first examination. In addition, the commanding officer of each battery was requested to furnish a list of suspects. The following letter was sent them:

It is requested that when men are sent for examination there will be a typewritten list of names, and that each battery commander be instructed to report on these lists any person suspected of being feeble-minded, insane, epileptic, habitual drunkard, dope fiend, pervert or criminal; and, in addition, to report persons who continuously show any of the following traits: irritability, seclusiveness, sulkiness, suspiciousness, melancholy, incorrigibility, timidity, shyness, silliness, foolishness, stupidity, slovenliness, bed wetting, somnambulism, with a written complaint in regard to each man deemed unfit for service.

I wish to state here that, in examination of other regiments, I have found that the officers can give the greatest help in picking up suspects, but in this particular regiment the men were practically all recruits, few of them having been in the service as long as three months, and the officers were changed so rapidly that they did not become acquainted with their men. The commanding officer of the regiment, for instance, was changed four times 
during the time I was examining it. In consequence, practically all suspects were picked up from the routine examination.

The method of examination is as follows: The men are stripped and step up as soon as the examination of the man in front of them is finished. A clerk writes down the data and only positive, $i$. e., abnormal, findings are recorded. Each man is asked his name, age and length of service. A few other questions are then asked as date, and place of birth, previous occupation, etc., to help in roughly guessing a man's mentality. Then the suspect is asked if anyone in his family has ever had any nervous breakdown, fainting attacks, epilepsy, fits or mental trouble. Next the same question is asked about the person examined. If any positive answers are obtained, further information is obtained. These replies constitute the family and personal histories, to which reference will be made later.

The neurological examination is conducted as follows: As the patient approaches the examiner, his gait is noted. A rapid glance is made for stigmata, which are not recorded unless pronounced. Needle (hypodermic) scars, are also looked for. The pupils are then examined by the aid of an electric flashlight, for outline, size and reaction to light. The suspect is then made to follow a moving finger with his eyes. In this way, the presence of strabismus, nystagmus, and paralysis of ocular muscles is determined; exophthalmos is also looked for. Next the suspect is made to show his teeth and put out his tongue, the mouth being hastily inspected. Tremors of tongue, lips or face, paralysis of face or tongue, and scars on tongue are noted. Enlargement of the thyroid is then palpated for. Next the suspect is asked to spread out his hands (tremor) and his grip is tested. If hyperthyroidism is suspected, the pulse rate is determined. The knee jerks are then taken, and if increased, Babinski and clonus are tested. Romberg and cordination (finger to finger) are tested and speech is examined by test phrases. All positive (abnormal) findings are recorded. Very slight alterations from the normal are not noted. During this whole examination, the suspect's mentality is sized up. A trained observer can really make quite a good guess as to a man's mentality simply from this brief test. Personally, I have found my results to be much better than I had anticipated. After a little practice, I found that I could examine a hundred cases a day in this way. 
After preliminary examination, the suspects are given such further examination as seems indicated, varying in length from a few minutes to several hours. In other words, each case is examined until it seems clear that the suspect either does or does not have a mental or nervous condition sufficient to disqualify him as a soldier. This includes the use of all the commonly accepted methods of mental and neurological examination which seem indicated in each case.

In all, I I 89 men were examined in the preliminary examination; I 68 men were picked for further examination but only I 44 were actually studied, for various reasons, in particular, the large number of transfers, which resulted in many men being sent away to other organizations in the interval between the preliminary and second examinations.

A few of the most important statistics from the preliminary examination are given and may be of interest.

I 89 cases were examined. 647 cases or 54.4 per cent were negative in every way. 542 cases or 45.6 per cent showed positive findings.

I 7 cases gave positive family histories of nervous and mental disorder, and in 40 of these cases all other findings were negative.

57 cases gave positive personal histories of nervous and mental disorder, and in none of these cases were all other findings negative.

475 cases gave positive findings from the neurological and mental examination and in 367 of these cases all other findings were negative.

The II 7 cases of positive family histories afforded the following data :

Nervousness, 54, in which 37 were of the mother, 5 of the father, 6 of $\mathrm{I}$ brother or sister, 6 of 2 or more brothers and sisters.

Fainting attacks, Io, in which 2 were of the mother, 2 of the father, 3 of $I$ brother or sister, 2 of 2 or more brothers and sisters, I of grandparent.

Epilepsy, 19, in which 3 were of the mother, 2 of the father, Io of I brother or sister, 2 of 2 or more brothers and sisters, 2 of uncle or aunt.

Goitre, 23, in which 8 were of the mother, 2 of the father, I3 of I brother and sister. 
$55^{8}$ EXAMINATION OF A REGIMENT IN U. S. ARMY [April

Insanity, 5, in which 4 were of the mother, I of I uncle or aunt.

Chorea, 3, in which 2 were of I brother or sister and I of I uncle or aunt.

Miscellaneous, 3 .

The $\mathbf{5 7}$ cases of positive personal histories yielded the following :

Nervousness, 39, fainting attacks 4 , epilepsy 8 , chorea 4 , miscellaneous 2.

The 475 cases with positive neurological and mental findings ran as follows:

69 cases showed sufficient evidence of mental deviation to warrant further examination. 59 of these were classed as possible mental defectives, 15 of whom were negative in every other way. Io were classed as possibly unstable emotionally.

Only a few of the most important neurological findings need be given.

7I cases showed the presence of several stigmata of degeneration.

I 2 cases showed pupillary changes.

9I cases showed sluggish reaction of the pupils.

2I cases showed unequal size or reaction of pupils.

93 cases showed thyroid changes.

65 cases showed slight enlargement of the thyroid.

20 cases showed the presence of small goitres.

4 cases showed the presence of medium size gottres.

I case showed the presence of a large goitre.

3 cases showed I lobe of the thyroid enlarged.

I 08 cases showed knee jerk changes.

70 cases showed exaggerated knee jerks.

5 cases showed greatly diminished knee jerks.

27 cases showed absent knee jerks.

6 cases showed unequal knee jerks.

I 26 cases showed the presence of tremors.

106 cases showed tremors of the fingers.

3 cases showed tremor of lips.

Io cases showed tremor of tongue.

7 cases showed tremors involving 2 or more of the above named parts. 
I 4 cases showed a slight stuttering or stammering.

35 cases showed combinations of alteration of pupils and alterations of jerks and tremors.

Io cases showed pupils sluggish, knee jerks exaggerated. 4 cases showed pupils sluggish, knee jerks diminished. 3 cases showed pupils sluggish, knee jerks absent. I case showed pupils sluggish, tremor fingers.

2 cases showed pupils sluggish, tremors fingers, knee jerks exaggerated.

I I cases showed knee jerks exaggerated, tremor fingers. 2 cases showed knee jerks absent, tremor fingers.

2 cases showed knee jerk absent, tremor fingers and tongue.

In the second examination, 144 cases were studied. The Wassermann test was done on 47 of these cases; the Binet test in 25 . I 3 cases suspected of 'mental defect were foreigners who spoke so little English that it was impossible to determine with satisfaction whether they were sufficiently defective to warrant their discharge, and they were accordingly returned to duty. About 20 were regarded as border-line cases, that is, it was felt that only more careful and prolonged study than was then possible would enable one to completely understand their condition and make proper recommendations. A written report on these 144 cases was sent to the regimental surgeon.

After thorough examination of these 144 cases, 27 were recommended for discharge. The diagnoses ${ }^{2}$ in these cases were as follows :

Defective mental development, 6 .

Defective mental development and epilepsy, 3 .

Defective mental development and constitutional inferiority, 3 .

Defective mental development and constitutional inferiority with psychosis, 3 .

Chorea, 3.

Exophthalmic goitre, 3 .

Exophthalmic goitre and defective mental development, I.

'These diagnoses follow the nomenclature of the Manual of the Medical Department. Recently the Surgeon General has ordered that the nomenclature adopted by the American Medico-Psychological Society in May, I9I7, be followed. 
Hyperthyroidism, I.

Hyperthyroidism and anxiety neurosis, $\mathrm{I}$.

Dementia præcox and drug addict, $\mathrm{I}$.

Epilepsy, grand mal, r.

Epilepsy, petit mal, I.

Constitutional psychopathic state, I.

A brief summary of each of these 27 cases follows:

I. Private H. G., I8 years old, prisoner. Had drawn his gun on his corporal. Unruly, sullen and irritable. On examination the following facts were obtained from him: His paternal grandfather, father and mother all died in hospitals for insane, patient was always irritable and had a bad temper. This, he said, ran in his family. Admitted using cocaine for the last year. Dreams of killing people. Says people are against him and trying to injure him, "But they don't do it ; I'll kill a couple." Admits hearing voices. Says he has heard them all his life. Voices abuse him and make him angry. Voices sometimes tell him to kill people. Has considerable insight, says "the whole damn family, we are crazy." In mood, he is sullen and irritable and suspicious. Physical examination was negative. Diagnosis: Dementia præcox, paranoid type. Drug habit (cocaine). It was recommended that this patient be sent to his state hospital for insane as a dangerous person.

2. Private L. H., 19 years old. Family history very incomplete. Mother has fainting attacks; one sister has epilepsy. Personal history: Went to school one term, then "shook all over and was sick" and was taken out. Has worked sweeping floors since 15. Mental state: Is 9 years old by Binet test. Mental defect very apparent. Cannot add 2 and 4 . Physical: Many stigmata, trembles when examined. Pupils a little sluggish, knee jerks exaggerated. Diagnosis: Defective mental development.

3. Private M. G., 29 years old. Family history: Very incomplete. Father has some vaguely defined nervous trouble. Personal history: Does not know when he was born. Spent five years in an ungraded school. Went to work at 15 and has worked as a laborer ever since. Has had typical epileptic convulsions. Has aura, then falls down unconscious in spasm. Has incontinence of fæces during attacks. Mental status: Binet test shows a mentality of 7 years. Mental defect is very apparent. No evidence of delusions or hallucinations. Physical: Essentially negative. Diagnosis: Epilepsy, defective mental development.

4. Private E. D., 24 years old. Family history: Mother and three sisters have chorea. Personal history: Has had attacks of chorea ever since he can remember. In an orphan asylum till 13 ; has worked on a farm ever since. Shortly after the preliminary examination he developed a typical attack of chorea and was brought into the hospital. Diagnosis: Chorea.

5. Private T. P. P., 23 years old. Family history: Negative. Personal history: Never very strong. Went to school till is but only reached the 5th grade. Always nervous, excitable, easily upset and this condition has 
been worse since he joined the army. Has attacks of palpitation. Mental status: Seems nervous and excitable. Binet test shows a mentality of 15 years. Physical: Moderate enlargement of thyroid, slight exophthalmos, pulse 100, tremor fingers. Diagnosis: Exophthalmic goitre.

6. Private J. O., I9 years old. Family history: Negative. Personal history: One year in school. Worked as laborer. Complains of nervousness, blackness before eyes and various hypochondriacal symptoms. Says he cannot do calisthenics. Mental status: Very dull and stupid. Nervous. Hypochrondriacal. Binet test shows a mentality of ro years. No evidence of delusions or hallucinations. Physical: Negative. Diagnosis: Defective mental development.

7. Private W. C., 19 years old. Family history: Father is nervous. Mother has manic depressive insanity. Both maternal grandparents and one paternal uncle were abnormal. Personal history: Never attended school regularly. Always peculiar. Never played with other children; kept to himself. States that he has always been unable to learn. Says that the other soldiers call him "crazy." Was in Mexico with Pershing's troops. Mental status: Binet test shows a mentality of 8 years. Is clearly below normal intelligence. Admits auditory hallucinations which have been present since a child but shows no evidence of delusional formations. Physical : Negative. Diagnosis: Constitutional psychopathic state.

8. Private V. M., 2I years old. Family history: Mother has spells when she gets nervous and excited and has to go and sit down. One sister has epileptiform convulsions. Personal history: Normal childhood. When about 9 years old he was sitting in the school room studying, when things turned black and he fell out of his seat. These attacks have continued up to the present time. Attacks are not all alike. Usually are preceded by a general tremor, then things turn black and he falls down. Hears people talking but cannot understand what they are saying, is unable to move. No incontinence. Often attacks only last a few seconds. Mental status: Not very high grade mentally. Shows some vague hallucinary mechanisms. Physical examination: Negative. Diagnosis: Epilepsy, petit mal.

9. Private J. P., 32 years old. Family history: Father alcoholic and irritable. Mother has large goitre; is a little nervous. One sister has spells of irritability. One brother is nervous like the patient. One brother weighed 200 pounds when 13 years old. Is high strung and has "rheumatism." Personal history: Normal childhood. Became nervous when about Io and was kept out of school some. Thinks he overstudied. Quit school when 13; has worked as a laborer since. Worked a good deal nights and did not sleep properly. Started drinking when about 16; sometimes would average to to 15 glasses of beer daily. Masturbated a good deal and read quack literature, which caused him to worry a good deal. Contracted gonorrhoea about seven years ago and did not have proper treatment. About five months after this he began to have auditory hallucinations; was confused and shook all over. This condition disappeared in a few days. Mental status: Is worrying and anxious. Has feelings of inadequacy and 
shows a rather typical masturbation complex. Has no hallucinations now. Has good insight. Physical examination shows a medium-sized goitre and coarse tremor of fingers. Complains of attacks of palpitation. Diagnosis: Anxiety neurosis. Hyperthyroidism.

10. Private R. W., 22 years old. Family history: Paternal grandfather had "nervous prostration" for 15 years preceding his death. Maternal grandfather was periodical drinker. Nervous and easily upset. Maternal grandmother always nervous and worried a great deal. Mother is nervous and easily upset. One brother is 18 and has quit school because of his "nerves." Personal history: Never strong, always nervous. Enuresis until I8. Had some sort of an operation for discharging ear when 9. Was so nervous after this that he was not allowed to go back to school but was sent on a farm where he stayed until he joined the army. Has had several attacks when things would get black and he would fall down, but did not lose consciousness. Finds it hard to do things. Sleeps poorly. "I don't like to be around people." Mental status: Is nervous, worried and discouraged. Binet test shows mentality of 9 years. Physical examination shows a coarse tremor of hands. Diagnosis: Constitutional inferiority. Defective mental development.

II. Private F., I7 years old. Family history: Maternal grandfather had chorea. Mother has epilepsy. One sister is nervous. Personal history: Normal childhood. One year in school; did not like it, so quit. Worked on farm most of life. Has spells when he shakes all over and feels numb. Reported by commanding officer as dull, stupid and incapable of learning. Mental status: Is dull and stupid and shows lack of understanding. Cannot read or write. Binet test shows mentality of Io years. Physical examination is negative. Diagnosis: Defective mental development.

12. Private E. De T., 22 years old. Family history: Father is nervous and easily upset and shakes all over. Mother is also nervous and easily upset. Personal history: Nothing known of early life. Never went to school. Ran away from home at $\mathbf{8}$ and has "bummed" from one town to another ever since. Never worked until about two years ago, but has worked fairly steadily since. Uses alcohol to excess. Has been arrested three times for "being drunk and raising the devil around town. Riding freight trains." Mental status: Appears of rather low intelligence. Shows a certain childish directness and lack of modesty in discussing his personal history. Seems quite proud of his ability to live without working and of his alcoholic excesses. Speaks of some vague, half-formed hallucinatory experiences. Binet test shows a mentality of 9 years. Physical examination was negative. Diagnosis: Constitutional inferiority. Defective mental development.

13. Private E. S., I9 years old. Family history: Father alcoholic, nervous and irritable. One maternal aunt insane. Three sisters are nervous, easily upset and irritable. Personal history: Little known of early life. Has had convulsions ever since a baby until four years ago. Would become unconscious and have clonic spasm. Often bit tongue. Went to school about seven years, then worked on a farm. Mental status: Seems rather childish and immature and not very bright. Binet test shows a men- 
tality of 9 years. His memory about the remote past is quite vague. $\mathrm{He}$ admits visual hallucinations. At night he sees white objects walking around. Physical examination: Negative. Diagnosis: Epilepsy. Defective mental development.

14. Private R. U., 21 years old. Family history: Negative. Is of Italian stock. Personal history: Uneventful. Born in Italy. Three years in school. Came to United States when II years old. Has worked as a laborer. He is said by his regimental commander to be dull and stupid and incapable of learning. Mental status: Binet test shows a mentality of 8 years and other tests confirm this. Diagnosis: Defective mental development.

I5. Private H. P., 28 years old. Family history: Mother insane. One maternal aunt alcoholic. One maternal aunt is a chronic invalid. One brother is Case 16 of this series. One brother belongs to the 12th Field Artillery. It is said that he ran away about a month ago and was caught and put in the hospital. Personal history: Little known of early history. Went to school two months; cannot read or write. Has worked as a laborer all his life. Mental status: Quiet, underactive, dull and stupid. Does not comprehend many things asked him and makes contradictory replies at times. Is somewhat vague and seems a little out of touch with the world of reality. Binet test shows a mentality of 9 years. Has hallucinatory experiences; sees claws coming across his face; sees a light "just like gold"; imagines that he is someone else; or "I imagine there is two of us"; "Don't know what you're doing half the time." Has considerable insight and realizes there is something the matter mentally. Physical examination shows many stigmata. Diagnosis: Constitutional inferiority with psychoses. Defective mental development.

16. Private L. P., 27 years old. A brother of H. P., Case 15. Personal history: Little known of early life. Never very strong. Entered school when 6; went irregularly until i3. Found school work very hard; was in second grade when he left. Worked at various jobs since; usually quit in a short time because he found the work too hard for him. Mental status: Is dull and stupid; no initiative; slightly undertalkative; rather apathetic. Speaks of some vague hallucinatory experience, "Sometimes I see something coming towards me in the dark; imagination." Binet test shows a mentality of to years. Has considerable insight; says he cannot learn as easily as most persons. Physical examination is negative. Diagnosis: Constitutional inferiority. Defective mental development.

17. Private E. S., 22 years old. Family history: Paternal grandfather insane. Mother and two maternal aunts have chorea. Personal history: "Spinal fever" at 2. Entered school at 6; went until ro, when he developed chorea and was out for two years. Returned and finished the 8th grade when 18. Worked on a farm most of the time prior to enlistment. Has had occasional slight attacks of chorea during this time. Complains that at present he is nervous; his eyes jerk at times; when standing at attention his knees "quiver." At times he feels as if he would fall down. Mental status: Essentially negative. Binet test shows correct replies for 15 years 
and some correct replies for adult. Shows some nervousness and hypochondria. Physical examination shows internal strabismus with dilopia. No tremors present at time of examination. Diagnosis: Chorea.

18. Private B. S., I9 years old. Family history: Father has epileptiform convulsions. One sister has had one convulsion when small. One sister is "weak and nervous." Personal history: Little known of early life. Replies are confused and contradictory. First convulsion occurred coming home from school. Fell down, unconscious, clonic spasm. Has been having convulsions ever since, frequently from two in the same day to intervals of two months apart. Has had convulsions several times since in army. Mental status: Seems very childish and quite dull. Will of ten break in with some remark absolutely unrelated to the conversation. Memory seems quite vague. Binet test shows a mentality of 9 years. Physical examination is negative. Diagnosis: Epilepsy. Defective mental development.

19. Private W. D. M., 24 years old. Family history: Father has neuralgia and is nervous. Mother was undernourished, highly excitable and worried. One brother has epilepsy. Personal history: Little known of early life save he went to school six years and was in the 7 th grade, but failed in his work about half the time. Worked at odd jobs; twice was a section foreman but could not make out his reports so was discharged. Has attacks now when he falls down; shakes all over; is unconscious and often has incontinence. At nights he has smothering attacks. Always gets dizzy on exertion. Has used alcohol since 14, often 3 to 12 whiskies daily. Mental status: Has auditory hallucinations. Hears voices. "They are always friendly and seem to be trying to help me." "They call my attention to things." "They read novels to me and try to teach me things." "They sound like real voices." "I don't know whether they are real people or not." Is quite dull. Binet test shows a mentality of 7 years. Says that his mind is affected. Physical examination shows a coarse tremor of hands and an area over left kidney where sensation is possibly diminished, but replies are so contradictory that this could not be satisfactorily determined. Diagnosis: Constitutional inferiority with psychosis. Defective mental development.

20. Private W. D. H., I9 years old. Family history: Mother nervous. One sister nervous and shakes all over at times. Personal history: Only a few months' schooling. Worked on a farm most of life. At present is bothered by weak, nervous spells and smothering attacks. Mental status: Seems dull and stupid. Binet test shows a mentality of 9 years. Is reported by his sergeant as being unable to learn. Occasionally he has auditory hallucinations; thinks he hears someone call him. Physical examination is negative. Diagnosis: Defective mental development.

21. Private A. J. J., 23 years old. Family history: Negative. Personal history: Normal childhood. School till 19. Studied electrical engineering but did not like it. Worked as timekeeper until he enlisted on June 2, 1917. He had an attack of tonsillitis shortly after this and then noticed that he could not button his shirt around his neck. The swelling in his neck has increased steadily. Has always been a little nervous, but more so lately. 
Has severe attacks of palpitation. Has had two attacks of diarrhcea recently and has lost about 15 pounds. Mental status: Negative, except he seems rather nervous and on edge. Physical examination: Slight exophthalmos, thyroid symmetrically enlarged, slight tremor of fingers, pulse II2. Diagnosis: Exophthalmic goitre.

22. Private G. T., I9 years old. Family history: Paternal grandfather, father and two paternal uncles are all described as nervous and worrying a good deal. Mother and one sister are chronic invalids. Personal history: Was prematurely born during severe illness of mother and only weighed three pounds at birth. Was sick first three years of life and never out of bed. Finished high school at 18 . Was nervous and had headaches so quit school and worked in an auto shop. Since in the army he is more nervous, worries, gets easily excited, at times shakes all over, has attacks of palpitation and of diarrhoea. Mental status: Is nervous. Can't sit still. Says he worries a good deal. Physical examination shows thyroid slightly enlarged, fine tremor of fingers, pulse 90. Diagnosis: Hyperthyroidism.

23. Private M. S., 22 years old. Family history: Maternal grandmother and mother are described as nervous. One brother is a little nervous and worries some. One half-sister had a goitre and now has extreme tremor of hands and is unable to sit still. Personal history: Little known of early life. Went to school irregularly until a year ago and worked on the farm. Reached 5th grade. Never very strong. During the last year has noticed a swelling in his neck which has gradually increased. Has also been more nervous, has worried and would get easily excited. Would have spells when he would tremble all over. Mental status: Nervous and worried. Quite dull and stupid. Binet test shows mentality of 9 years. Physical examination shows marked exophthalmos, medium-sized goitre, tremor of fingers, pulse 92. Diagnosis: Exophthalmic goitre. Defective mental development.

24. Private J. B., 25 years old. Family history: Nothing known of grandparents, uncles and aunts. Father has a goitre and is very nervous. Mother has a goitre, "is sick all the time." Four sisters are nervous and have tremor of hands. Two sisters have goitres, are very nervous and easily frightened. Personal history: Can give few details of early life, apparently too stupid to remember. Only went to school one month. Swept out a store when 12. Kept at it three years, then loafed three years. Then left home because "they were always chewing the rag and fighting." Worked in lumber company two years, then started bumming around the country. Would work only a few days at a time. Got drunk "whenever I got the chance." One time was drunk for two months, having saved $\$ 300$ for this purpose. Used cocaine for a short time six years ago, but says he quit because it made him more nervous. Has averaged 20 to 40 cigarettes daily. Says he is nervous, easily excited and worries, but will not discuss his worries frankly, though admitting they have to do with sex matters. Mental status: Is very dull, stupid, and unintelligent. Binet test shows a mentality of 9 years. Admits hearing voices, apparently is not very frank and open. Physical examination shows a coarse tremor of fingers. 
Diagnosis: Constitutional inferiority with psychosis. Defective mental development.

25. Private A. E., 25 years old. Family history: Paternal grandmother had epileptiform convulsions. Father is very nervous and trembles at the least excitement. One paternal uncle committed suicide when depressed. One paternal aunt is in poor health, nervous and worries a good deal. Maternal grandfather had exophthalmic goitre. Mother and three maternal aunts have epileptiform convulsions. Two brothers are nervous and excitable. One brother and one sister have epileptiform convulsions. Personal history: Sickly as a baby. School 6 to 14 . Finished 7 th grade. Commenced to have convulsions when 8 , which have persisted up to the present time. From 14 to 21 was a call boy, then a fireman on switch engine for two and a half years. Quit because he had several convulsions on the engine. Drove a team until he enlisted in the army, April, 19r6. Convulsions have persisted and he has twice had them in the army hospital. A typical convulsion is as follows: Aura consisting of weakness and sweating. Suddenly he falls back without any warning and is unconscious. There is a short tonic spasm, followed by clonic spasms involving all parts of the body. There is gritting of teeth. Often he bites his tongue and there is bladder incontinence. Patient has averaged four to five whiskies daily. Mental status: Says he hears a male voice warning him at times. Does not know whether this voice is real or not. Physical examination, negative. Diagnosis: Epilepsy.

26. Private G. B., 2I years old. Family history: Father and mother both very neurotic. One paternal uncle insane. Two brothers have facial tics and twitchings of their shoulders. Personal history: Sickly as a child. Finished the 6th grade when 14 ; did not go to school regularly because of health. Worked in a dry goods store and then in a shoe factory. Has had attacks of chorea ever since about 6 years old, but these have been absent for the last two years. At present is bothered by extreme nervousness, feels as if he were about to have another attack. Mental status: Negative, except that he seems nervous, easily excited and keeps fidgeting at things. Seems unable to sit still. Physical examination negative. Diagnosis: Chorea.

27. Private P. F., 35 years old. Family history negative. Personal history: Patient's account is unsatisfactory; he often says he cannot remember things. No history of severe illness. Practically no schooling; cannot read or write. Has worked at various jobs, mostly unskilled labor. Has been twice arrested for vagrancy. Mental status: Seems very childish and immature; cries if spoken to sharply. Is extremely dull and stupid. Mentality 8 years by Binet test. Physical: Has a chronic arthritis in left hip and complains of pains in various parts of the body. Diagnosis: Defective mental development.

The results may briefly be summed as follows: By the use of a rapid routine examination and a second examination of suspects, a regiment of II 89 men were examined for nervous and mental 
diseases. As a result, 27 men or 2.2 per cent were found to be suffering from nervous or mental disease in sufficient degree to warrant their discharge.

And to generalize these conclusions: There are at present throughout the army, and more especially among those organizations composed of recruits, a considerable number of cases of nervous and mental diseases. By the examination outlined in this article many of these cases can be detected and discharged, thus freeing the army of men who not only would be of no value but who would be a burden and detriment to the service. 